\title{
Timor Etnográfico : antropologia e arquivo colonial
}

Ethnographic Timor: anthropology and the colonial archive

\section{Ricardo Roque}

\section{(2) OpenEdition}

Journals

Edição electrónica

URL: https://journals.openedition.org/aa/1828

DOI: $10.4000 /$ aa. 1828

ISSN: 2357-738X

\section{Editora}

Programa de Pós-Graduação em Antropologia Social (UnB)

\section{Edição impressa}

Data de publição: 1 dezembro 2017

Paginação: 9-29

ISSN: 0102-4302

\section{Refêrencia eletrónica}

Ricardo Roque, «Timor Etnográfico : antropologia e arquivo colonial», Anuário Antropológico [Online], v. 42 n.2 | 2017, posto online no dia 12 junho 2018, consultado o 18 maio 2021. URL: http:// journals.openedition.org/aa/1828 ; DOl: https://doi.org/10.4000/aa.1828

\section{(c) (1) (8)}

Anuário Antropológico is licensed under a Creative Commons Atribuição-Uso Não-Comercial-Proibição de realização de Obras Derivadas 4.0 International. 


\title{
Timor Etnográfico: antropologia e arquivo colonial ${ }^{1}$
}

\author{
Ricardo Roque \\ Instituto de Ciências Sociais da Universidade de Lisboa
}

O dossiê Timor etnográfico: antropologia e arquivo colonial explora os arquivos documentais do império português tardio com vista a entender o processo de constituição de povos e culturas leste-timorenses como objetos etnográficos em situação colonial. O dossiê abarca um leque amplo de temas e formas de conhecimento: o estudo dos múltiplos artigos e livros produzidos no quadro de relaçóes coloniais no âmbito da administração e da atividade missionária; o trabalho de campo e produção científica enquadrados pelas campanhas das missóes antropológicas promovidas pelo Estado imperial; e, por fim, a emergência de uma cultura literária e cinematográfica associada à imaginaçáo de culturas, costumes, raças e línguas de Timor. Os artigos mostram como a objectivaçáo de Timor e suas populaçóes tomou a forma de um conjunto diverso de saberes coloniais de tipo etnográfico, fundado em observação de terreno, desde o início do século XX até ao final da administração portuguesa em 1975.

Neste período histórico, antes ainda da consolidação de uma antropologia social e cultural académica e profissional sobre o território, a imaginação política de um Timor Português foi acompanhada de uma variedade de textos e imagens de vincada natureza etnográfica. A emergência, em língua portuguesa, deste universo discursivo e reflexivo sobre a alteridade dos timorenses indica, como sugere o título deste dossiê, a existência de um Timor etnográfico no interior da ordem colonial. Os conteúdos e os contornos deste Timor etnográfico colonial não equivalem ao desenho disciplinar da antropologia social e cultural contemporânea. A sua compreensão historiográfica exige um esforço de descentramento disciplinar, capaz de se dispor a entender a especificidade dessas etnografias coloniais nos seus próprios termos. Por conseguinte, os ensaios de história da antropologia aqui reunidos não estão orientados por uma retrospecção genealógica de tipo disciplinar. Entendemos que esse recorte impediria o reconhecimento efetivo da diversidade de práticas e praticantes de etnografias coloniais, nomeadamente daquelas representadas pelo trabalho de missionários, administradores, militares e mesmo por antropo(bió)logos que acabariam secundarizadas nas historiografias oficiais da disciplina da antropologia social e cultural portuguesa (Roque, 2001). 
Ao invés, adoptamos uma noção heurística e aberta de etnografia enquanto regime plural de práticas de observação e escrita, fundadas em experiência de terreno, visando o conhecimento da vida sociocultural timorense. Através desta, interessa-nos restituir a multiplicidade de registos, intencionalmente etnográficos, $\mathrm{da}$ alteridade timorense na forma de textos e imagens e o modo como esses registos estão marcados por uma situação colonial.

Após a revolução de abril de 1974, a história da antropologia (social e cultural) portuguesa tendeu a desvalorizar as tradiçóes coloniais de antropologia em prol de narrativas de origem que, quase exclusivamente (à exceção talvez da obra de Jorge Dias sobre os Macondes de Moçambique, produzida na década de 1960), reconheciam no estudo dos povos rurais metropolitanos as fundaçóes modernas da disciplina (Leal, 2000, 2006; Pereira, 1998; Pina-Cabral, 1991). No início da década de 2000, produzi uma crítica aos limites destas perspectivas, propondo em alternativa um "inquérito às práticas plurais de conhecimento antropológico" acerca das populaçóes do império português (Pereira, 1989; Roque, 2001:281286). Posteriormente, em linhas que creio consonantes com esta crítica, essa restrita genealogia disciplinar tem continuado a ser objeto de revisão historiográfica, quer por antropólogos, quer por historiadores da antropologia. Hoje, aceitam-se visóes mais porosas e plurais do passado disciplinar, reconhecendo-se coexistências complexas e trânsitos e cumplicidades variadas entre antropologias coloniais e metropolitanas; entre tradiçóes "física" e "cultural" da antropologia; ou, enfim, entre universos académicos e saberes associados aos aparelhos políticos e administrativos do Estado e da Igreja (mas compare-se, por exemplo, Almeida, 2008; Leal, 2006; Pereira, 2004-2005; Roque, 2010; Thomaz, 2001; Viegas \& Pina-Cabral, 2014).

É indiscutível a profunda marca do enfoque em raízes populares e a obsessão intelectual com a identidade nacional nas diversas modalidades da antropologia portuguesa no século XX. Contudo, é ainda necessário questionar a ideia de que essa fixaçáo com a identidade nacional se desenvolveu a expensas de um desinteresse sistemático pelo estudo de cariz antropológico das identidades étnicas, raciais, sociais e culturais das populaçóes nativas do império português. A ideia, para usar das palavras de João Leal num (todavia) estimulante artigo, de que náo surgiu "qualquer tradição sistemática de antropologia social colonial em Portugal até ao final dos anos 50", embora o império permanecesse uma "sombra" ou "subtexto" da antropologia portuguesa (Leal, 2006:64), só é talvez válida se, imaginariamente, elidirmos do registo documental os inúmeros e sucessivos textos e livros de conteúdos mesmo autodeclaradamente "etnográficos", produzidos por missionários, administradores, militares, governadores e funcionários coloniais. 
Por esse motivo, é pertinente reconhecer a perseverança, durante o século XX, de tradiçóes etnográficas coloniais e desenvolver um inquérito comparado às mudanças e à pluralidade das suas manifestaçôes nos vários espaços coloniais de expressáo portuguesa.

É enquanto contributo para este inquérito à diversidade das etnografias emergentes no império colonial português que se apresenta este dossiê. Além disso, no contexto dos estudos sobre Timor-Leste - um campo interdisciplinar, desde 2000 dominantemente anglófono -, não será demais insistir na importância de uma perspectiva crítica e inclusiva da antropologia de Timor que considere o arquivo etnográfico colonial produzido em língua portuguesa. ${ }^{2}$

Pois cremos que é não apenas dentro, mas também fora das normas disciplinares, teóricas, profissionais e até ético-morais da "antropologia social e cultural" pós-colonial que os arquivos etnográficos de Timor se devem procurar, ler e estudar criticamente. $\mathrm{Na}$ mesma medida em que as antropologias anglófonas e francófonas sobre Timor ganharam ascendência, as etnografias de expressáo portuguesa praticadas pelos antigos agentes coloniais remeteram-se a nichos lusófonos (ou lusófilos) de relativa invisibilidade, acabando numa espécie de circuito fechado. Esta relativa invisibilidade teve razões disciplinares, linguísticas e políticas contextuais. No que toca a Timor-Leste, estas razões em parte remontam ao processo de afirmaçáo, nas décadas finais da presença colonial portuguesa, de etnografias internacionais enquadradas disciplinarmente pela "antropologia social" (na tradição britânica) ou pela "etnologia" (na tradição francesa), como se depreende, aqui, da contribuição de Cláudia Castelo (2017).

Esta invisibilidade nos textos da etnografia profissional das décadas de 1960 e 1970 - notória no tardio mas revelador reconhecimento do contributo das etnografias coloniais portuguesas pelo antropólogo britânico David Hicks (2011) - só recentemente se vem dissipando, por força do interesse crescente dos antropólogos sociais e culturais (e não apenas daqueles falantes de língua portuguesa) em explorar a fundo os conteúdos do arquivo colonial português sobre Timor-Leste. Os artigos aqui reunidos consideram, assim, antropologias associadas à condiçáo colonial de Timor Português, explorando uma profusão de escritos e imagens de natureza etnográfica (e também etnoarqueológica, no caso do artigo de Poloni) que se inscrevem em circunstâncias coloniais de conversão, administração e investigação científica - e de onde, em vários casos, relaçóes de poder e violência não estão ausentes.

O dossiê tem origem no trabalho de equipa desenvolvido, ao longo de três anos (2010-2013), no âmbito do projeto de pesquisa As ciências da classificação antropológica em Timor Português, financiado pela Fundação para a Ciência e 
Tecnologia e desenvolvido no Instituto de Ciências Sociais da Universidade de Lisboa. Este projeto propôs-se investigar as histórias interligadas da antropologia de povos indígenas e do colonialismo português ao longo do século $\mathrm{XX}$, tendo como referência o espaço de Timor Leste, denominado Timor Português durante o período colonial tardio. Para efeitos heurísticos, o projeto tomou como campo empírico o que se designou de "ciências da classificação antropológica", isto é, os regimes epistémicos e as disciplinas científicas dirigidas à ordenação das diferenças e afinidades biológicas, linguísticas e socioculturais entre populaçôes humanas. Assim, o estudo considerou um conjunto diverso de métodos e tradiçóes disciplinares da "antropologia", desde abordagens bioantropológicas (craniologia, antropometria, seroantropologia) a perspectivas socioculturais (tais como filologia comparativa, antropologia social e cultural). Considerou, igualmente, um espectro amplo de instituiçóes e praticantes, desde agentes coloniais (missionários, administradores, militares) a universitários metropolitanos, quer portugueses, quer internacionais.

Foi central a este projeto a hipótese de que a classificação antropológica e a ordem colonial devem ser tratadas como temas entrelaçados e processos interdependentes. Esta ampla hipótese foi abordada através de um enfoque num caso empírico revelador: o trabalho investido por militares, funcionários, missionários e académicos portugueses no estudo de "raças", "línguas" e "culturas" de Timor Português entre as décadas finais do século XIX e 1975, data da ocupação indonésia do território e do fim da administração portuguesa. Considerámos Timor como laboratório histórico para explorar os motivos, conteúdos e impactos das iniciativas tomadas pelos colonizadores europeus para objectivar e classificar outros povos e costumes - mas também como laboratório privilegiado para evidenciar as tensóes coloniais e pós-coloniais inerentes a esse programa. Colónia portuguesa até 1975, Timor permaneceu esquecido e marginal no império português por longas décadas, prevalecendo na metrópole uma valoração geralmente negativa da colónia e suas populaçôes. Na década de 1940, em face da violenta ocupação pelas tropas japonesas durante a Segunda Guerra Mundial, Timor foi catapultado para o centro do imaginário imperial português, ganhando um destaque inusitado no ideário nacionalista e luso-tropical do pósguerra - o qual, como aqui testemunham os ensaios de Castelo, Poloni e Piçarra, se acompanhou de um inédito investimento do Estado colonial na investigaçáo científico-antropológica em Timor.

Não obstante o carácter tardio deste interesse positivado da administraçáo portuguesa por Timor, os seus povos foram objecto de um invulgar interesse antropológico internacional desde o século XIX. Das origens da etnologia europeia 
até aos longos debates sobre a linha etnológica de Wallace, Timor despertou o interesse científico de holandeses, franceses, alemães e britânicos (Roque, 2010). Em Portugal, foram feitos esforços ténues para resolver cientificamente esse problema etnológico, mas em realidade só no século XX Timor se fixou como objeto de uma antropologia académica de carácter marcadamente nacional e nacionalista, engajada com o projecto colonial - compare-se, para dois panoramas desta literatura, Schouten (2001) e Gunn (2009). Assim, na década de 1930, Timor Português surgiu como objecto destacado de uma nova disciplina científica, a "antropologia colonial portuguesa", liderada pelo influente académico portuense António Mendes Correia. Nos anos de 1950, este interesse de Correia por Timor resultou em expediçóes de pesquisa de terreno em "antropologia colonial" lançadas desde a metrópole, a chamada Missão Antropológica de Timor (MAT), liderada pelo médico e antropólogo António de Almeida. Porém, já desde finais do século XIX e mais ainda na primeira metade do século XX, a escrita etnográfica sobre Timor se praticava no terreno por militares, funcionários, governadores e missionários coloniais, muitas vezes no âmbito de atividades administrativas, militares e religiosas de colonização.

Paralelamente a estes esforços oficiais vincadamente coloniais e nacionalistas, o interesse internacional por Timor recrudescia, no contexto do interesse da antropologia social e cultural, pelas sociedades da Ásia-Pacífico. Neste quadro, nos anos de 1960, ainda que sem abdicar de um patriotismo imperial católico e humanista, o influente agrónomo e poeta Ruy Cinatti abraçaria a antropologia social; por seu intermédio, o terreno de Timor Português abrir-se-ia aos apetites da moderna etnografia profissional académica baseada em trabalho de campo intensivo. Timor reinscrever-se-ia assim no novo mapa da discussão antropológica - embora, agora, restando ao mundo das etnografias coloniais um lugar menor, senão mesmo apagado, neste processo. Superado o vazio etnográfico imposto pela violenta ocupação indonésia entre 1975 e 1999, o estudo antropológico de TimorLeste ganhou um novo e vibrante impulso (Gunn, 2007). Na contemporaneidade, desde a data da independência do país, em 2000, existe em torno de Timor-Leste um campo fértil de produção etnográfica e teórica em antropologia (por exemplo, McWilliam \& Traube, 2011). Neste contexto, despertos para a relevância actual do renascimento, poderá dizer-se, de um "Timor-Leste etnográfico", foi também nosso objectivo pensar conexóes entre a pesquisa histórica e a contemporaneidade. Deste modo, a equipa almejou contribuir igualmente para uma reflexão contemporânea sobre as relaçôes entre a historicidade colonial e a produção etnográfica passada e presente em Timor-Leste (Roque \& Traube, em preparação). 
Este dossiê constitui, assim, uma expressão parcial deste amplo projeto, pelo que o objectivo é mais circunscrito. Aqui, partimos do princípio de que o interesse de missionários, administradores, militares e antropólogos profissionais por este território e pelas suas populaçóes deu origem a um rico arquivo etnográfico, o qual, uma vez sujeito à necessária crítica histórica e conceptual, pode dar acesso a novos ângulos de interpretação da realidade cultural timorense, tanto quanto da realidade política da colonização portuguesa. Em todo caso, ao identificar a pertinência de um Timor etnográfico colonial, este dossiê não restringe a sua relevância à especificidade empírica do seu objeto histórico; ele convida a uma expansão mais geral do horizonte de análise dos saberes antropológicos de terreno no espaço do império português - bem como dos seus impactes no presente.

\section{II}

Os artigos aqui reunidos cobrem principalmente o arco cronológico que vai do dealbar do Estado Novo, nas décadas de 1920 e 1930, à década de 1960 e aos anos finais do regime colonial em Timor-Leste. Este recorte espelha a intensidade das transformaçóes no campo local das etnografias coloniais de Timor nas décadas que sucederam à ocupação japonesa do território durante a Segunda Guerra Mundial. Nesse período - como veremos de seguida, na descrição comentada de cada artigo -, assistimos à interação (por vezes colisão) entre as etnografias coloniais que até então estavam na alçada dos agentes coloniais, com novos modelos de prática e autoridade antropológica. Nas décadas de 1950 e 1960, no quadro da política colonial de "ocupação científica", profissionais académicos da metrópole apoiados pelo Estado imperial - através da Junta das Missões Geográficas e Investigaçóes Coloniais ou do Ultramar, mais tarde renomeada Junta de Investigaçóes do Ultramar (JIU) (Castelo, 2012) -, reclamaram sobre Timor etnográfico uma autoridade científica superior (embora, em muitos aspectos, cúmplice) à dos administradores e missionários etnógrafos locais. No campo da antropologia, este processo de nacionalização da soberania científica encabeçado pelos experts da JIU encontrou na organização da MAT, dirigida por António de Almeida, a sua expressáo mais acabada. A par do desafio representado por este processo, as etnografias coloniais coexistirão ainda com o ímpeto internacionalizador representado pela etnografia profissional praticada por estrangeiros ao país, a qual, através da influência de Ruy Cinatti, faria de Timor um terreno de eleição para etnografias intensivas de comunidade, de moldes metodológicos malinowskianos, e enquadradas então por parâmetros teóricos dominantemente estruturalistas (Hicks, 2011). 
Os artigos deste dossiê propóem, então, uma viagem histórica e analítica por alguns dos principais personagens e acontecimentos que, desde os anos 20 e 30 do século XX, fizeram de Timor Português um objeto etnográfico imbricado com a condição colonial. Iniciamos o trajeto com uma exploração do arquivo etnográfico missionário. Em Timor, as antropologias missionárias estiveram associadas, desde o século XIX, à recolha e estandardização das línguas vernaculares timorenses (Cardoso, 2017). No artigo que abre este dossiê, Frederico Delgado Rosa explora outra dimensão importante do projeto antropológico missionário. Ele considera o complexo universo das "antropologias católicas" em Timor-Leste, interrogandose sobre a fixação dos missionários portugueses em isolar - e, no final, em julgar, converter e eliminar - os elementos fundamentais da "religião timorense" em seu estado "pré-colonial” e "primitivo". Em Timor, entre 1910 e 1974, e em tensão com o apelo "missiológico" ao reconhecimento de Deus nas religióes "pagás" nativas, os textos etnográficos de missionários examinados por Rosa revelam um "discurso antissincrético". Neste discurso, a religiosidade timorense surgia como negativo absoluto das virtudes morais e salvíficas do cristianismo, pouco mais do que "temor e orgias". Esta visão antropológica negativa, como demonstra o autor, acarretava uma visão da história colonial em Timor assente na "negação" de sincretismo religioso desde o século XVI.

Neste sentido, as antropologias católicas apresentam-se também com uma singular forma de antropologia histórica. "O desafio maior", escreve Rosa, "está em compreender a negação (mais do que a própria rejeição) de qualquer forma de sincretismo resultante da longa interação entre o cristianismo e a religião timorense". Para este efeito, Rosa concentra a sua atenção no modo como o problema das apropriaçóes nativas do catolicismo - nomeadamente o chamado "culto dos lulik" - foi enjeitado pela Igreja em Timor. Exemplo maior desta abordagem encontrase nos textos de um dos mais prolíficos e fascinantes autores da antropologia católica em Timor no século XX - o missionário e etnógrafo Padre Ezequiel Enes Pascoal -, mas poderá encontrar-se também, sugere Rosa, nos raros escritos etnográficos de catequistas timorenses nativos. Esta antropologia antissincrética apostava na negaçáo deste universo timorense a ponto de resultar em processos de destruição de antigo património lulik (sagrado, proibido) dos timorenses. Mas, como sugere Rosa, esta destruição era também, por vezes, um género de "autodestruiçáo", dado que entre os objectos lulik desprezados e condenados pela Igreja podiam estar também antigas imagens e santos católicos, que os timorenses haviam tornado lulik em tempos passados. O discurso antropológico que negava o facto histórico da indigenização "animista" do catolicismo era acompanhado por formas concretas de violência colonial. Não obstante, o arquivo missionário 
em Timor não deixa de mobilizar um tipo de reflexão antropológico-histórica sobre o problema do sincretismo, quiçá até dialogante em parte com preocupaçóes antropológicas atuais: "em certa sintonia com a perspectiva missionária", conclui Delgado Rosa, "é possível admitir que Timor Leste, visualizado em diacronia profunda, foi palco de apropriaçôes seletivas que integraram e por conseguinte preservaram padróes religiosos predominantemente nativos".

O ensaio de Delgado Rosa expóe a complexidade epistemológica e política das etnografias missionárias, à luz dos seus limites e possibilidades interpretativas. O seguinte artigo do dossiê, da autoria de Lúcio Sousa, é exemplo da relevância de outro género etnográfico colonial - as etnografias administrativas. Sousa dirige o seu inquérito histórico e crítico para um singular (e raramente tratado) núcleo arquivístico das etnografias coloniais portuguesas em Timor-Leste: as chamadas "monografias etnográficas originais". O autor parte de uma descoberta documental no espólio de Ruy Cinatti - um conjunto de oito monografias etnográficas de 1948-49, da autoria de administradores coloniais - para colocar interrogaçóes sobre as origens e o significado destes artefactos intelectuais. Instituídas na década de 1940 pelo Estado imperial, a cuja produção estavam obrigados (por requisito de progressão de carreira) os candidatos a "administradores de posto", as monografias sinalizam desde logo a importância que era atribuída à "etnografia e etnologia colonial” na construção do papel, das competências e da carreira do pessoal da administração colonial. Desde o final do século XIX, a etnologia foi sendo consagrada no quadro do ensino colonial como um saber necessário ao bom governo dos povos indígenas nas colónias. Neste sentido, o ensino da etnografia colonial consolidou-se em instituições metropolitanas como base de um treinamento "científico" de funcionários ultramarinos. Primeiro, no quadro da Escola Superior Colonial, criada em 1906 em Lisboa e, décadas mais tarde, de forma reformada e reforçada no quadro do Instituto Superior de Estudos Ultramarinos.

É neste contexto de institucionalização da "etnografia colonial" no quadro do sistema educativo metropolitano que Sousa situa a génese das "monografias etnográficas”. Fazendo uma análise de conteúdo das oito monografias, Sousa identifica as principais temáticas abordadas, o tipo de relação com os informantes, o universo intelectual de referências bibliográficas e o modo como tratavam a questáo da "mudança" cultural no quadro das interaçóes coloniais. Estas etnografias administrativas, tal como os textos missionários analisados por Rosa, acompanhavam-se da reclamaçâo, para si mesmas, de uma autoridade epistémica exclusiva e soberana, ao mesmo tempo que projetavam uma visão negativa da alteridade cultural timorense que se lhes apresentava quase inacessível e silenciosa. 
Para a sensação de opacidade (ou até resistência dos informadores) terá concorrido, como sugere Sousa, o facto de o trabalho dos administradores-etnógrafos se justapor a um exercício coercivo e fiscalizador de governo colonial.

Apesar do seu claro sentido "aplicado", estas monografias presumiam um tipo de saber sobre as sociedades nativas fundado em observação direta e experiência de campo, de um tipo, poderá dizer-se, etnoadministrativo. "Estes são pois documentos marcados por uma intencionalidade, diria, propriamente etnográfica," conclui Sousa, "à qual subjaz um sentido propriamente colonial uma narrativa a um tempo propedêutica e legitimadora da ação colonizadora da administraçáo." Presumiam também conhecimento de literatura científica, embora, como denota Sousa, um conhecimento limitado em boa parte à etnologia de Oitocentos e aos autores canónicos da "antropologia colonial" portuguesa. Por conseguinte, também nestes textos coloniais e administrativos - e, uma vez mais, tal como nos escritos missionários estudados por Rosa - pode reconhecer-se (subordinado, todavia, às deturpaçóes de interpretação do Outro que impunham os regimes de governo e moralidade "civilizatória" do colonizador) um certo entendimento da transformaçáo histórica dos costumes timorenses decorrente do contacto colonial.

Os artigos de Rosa e Sousa expóem a vivacidade da prática etnográfica protagonizada por agentes da administraçáo colonial - quer civis, quer religiosos - em Timor Português no século XX. A ligação destas etnografias aos contextos práticos da administração (civil, militar e eclesiástica) era profunda e evidente. Como revelam os autores, os textos decorrentes deste tipo de etnografias coloniais apresentam-se intencionalmente associados a programas de colonização, marcados ora pelos ideários de evangelização e conversão ao cristianismo, ora por uma agenda controladora da administração, apostada no governo das populaçóes e da paisagem, na extraçáo de recursos e na transformação dos nativos. Após a década de 1950, este universo etnográfico, arreigado na colónia de há várias décadas, ver-se-á acompanhado de novos tipos de praticantes de etnografia científica (quer de origem nacional, quer internacional). A relação entre estes mundos coexistentes de praticantes será doravante complexa, por vezes cúmplice, mas nem sempre pacífica.

Nas décadas de 1950 e 1960, com o selo do Estado, atuou no território a MAT, financiada pela Junta das Missões Geográficas e Investigaçôes Coloniais e chefiada pelo antropólogo colonial português António de Almeida. Com um programa de pesquisa polifacetado que aliava etnografia, pré-história e antropologia física (com esta última à cabeça), a MAT e o seu líder davam corpo à visão política do influente professor de antropologia da Universidade de Porto, António Mendes 
Correia, abraçada nos anos de 1930 e 1940 pelo governo de Lisboa. Isto é: a instituição de uma nova antropologia colonial de terreno, ao serviço da governação colonial, assente em expedições científicas metropolitanas (chamadas de "missóes antropológicas") tuteladas pelo Estado português, apoiadas pelas administraçóes coloniais locais e comandadas por autorizados especialistas académicos nacionais da metrópole. É também nestas décadas que, coexistindo com o programa antropo(bio)lógico da MAT, se destaca em Timor um outro protagonista, também ele funcionário administrativo na colónia: o poeta e engenheiro agrónomo Ruy Cinatti, um bem-nascido filho de diplomata com relaçôes pessoais, próximas e privilegiadas com algumas das mais altas figuras do regime do Estado Novo (entre eles, Marcelo Caetano e Krus Abecasis). Na década de 1950, o agrónomo Cinatti converter-se-ia à investigação em antropologia social - daqui derivando consequências importantes para o futuro da antropologia em Timor-Leste.

É justamente Ruy Cinatti o protagonista do artigo de Cláudia Castelo. Castelo investiga as origens intelectuais e biográficas da conversão de Cinatti à antropologia social e cultural, realçando o seu subsequente papel na "abertura" do terreno colonial de Timor Português à pesquisa etnográfica feita por antropólogos sociais “estrangeiros", oriundos de universidades americanas, francesas e britânicas. Como demonstra Castelo, a ação individual de Cinatti foi determinante para que a empresa etnográfica em situação colonial não se restringisse ao trabalho local dos agentes administrativos e aos horizontes nacionais da "antropologia colonial" portuguesa, passando, doravante, a integrar a vibrante cena internacional da "antropologia social e cultural". O modelo colonial português encontrava-se sob contestação internacional e a entrada de cientistas nas colónias era objecto de redobrada vigilância. Todavia, o pragmatismo do regime (sensível às vantagens de uma controlada internacionalização), o patriotismo de Ruy Cinatti, as suas boas relaçóes pessoais com as autoridades ministeriais e a sua invulgar rede de relações científicas capaz de ligar Oxford (onde chegou a cursar antropologia), Sidney, Paris, Lisboa e Díli contribuiu para que, na década de 1960, Cinatti se tornasse autoridade incontornável e verdadeiro gatekeeper no acesso à colónia para investigação etnográfica.

"Na década de 1960, o seu papel de intermediário", conclui Cláudia Castelo, "avalizado pela JIU e pelo Ministério do Ultramar, foi uma estratégia para afirmar a sua credibilidade como o especialista imprescindível de Timor Português, mas também reforçar o prestígio e a prioridade científica nacionais, num contexto político internacional desfavorável ao império colonial português". Baseada em exaustivo trabalho de pesquisa na documentação de Ruy Cinatti, Castelo expóe assim a teia de conexôes e circunstâncias biográficas que permitiram a 
Cinatti ganhar posição privilegiada como expert em Timor, quer perante as autoridades políticas do regime colonial, quer perante as autoridades científicas da antropologia social anglófona e francófona. Castelo destaca a importância da relação com o antropólogo australiano E. P. Elkin, de quem Cinatti bebeu uma visão humanista e desenvolvimentista, de cariz cristá, da antropologia centrada na promoção do bem-estar e na valorização empática das culturas e modos de ser dos timorenses. Assente nesta visão, Cinatti geriu o interesse das antropologias francesa e inglesa pelo estudo das sociedades do Sudeste Asiático, acabando por abrir Timor a estudos de orientação estruturalista e funcionalista - enquadramentos analíticos que, paradoxalmente, desagradavam ao estilo de antropologia humanista de Cinatti.

Embora, na prática, o "terreno etnográfico" continuasse a assentar numa situação colonial, o "Timor etnográfico" internacionalizado aberto por Cinatti vinculava-se a debates antropológicos que decorriam em Oxford e Paris e ao modelo de antropologia social e cultural que dominava as grandes universidades europeias e americanas. $\mathrm{O}$ género de saber que decorreria destas etnografias não se identificava, pois, com aquele que vinha sendo apanágio dos administradores e dos missionários portugueses, tampouco com os parâmetros da antropologia colonial portuguesa tutelada por Mendes Correia e prosseguida em Timor por um dos seus mais leais correligionários, António de Almeida. As etnografias coloniais praticadas por administradores, missionários ou militares, porém, não desapareceram simplesmente. Pelo contrário: o que os textos de Sousa, Rosa e Castelo sugerem é um complexo processo de coexistências, mais do que substituição, entre formas de entender e praticar "etnografia" em terrenos coloniais.

A este respeito, o texto de Cláudia Castelo ajuda a perceber que a internacionalização de "Timor etnográfico" na década de 1960 se deveu a circunstâncias que combinaram alianças internacionais e disputas nacionais, com Cinatti ao centro. No verso positivo da autoridade adquirida por Cinatti esteve uma dupla aliança às autoridades políticas portuguesas, por um lado, e à comunidade académica da antropologia social anglófona e francófona, por outro. Mas no verso negativo deste mesmo processo, e talvez não menos importante, esteve uma disputa nacional por autoridade científica. Como refere Castelo, o investimento de Cinatti na antropologia social e cultural estrangeira é indissociável da sua crítica às etnografias administrativas dos funcionários coloniais, bem como à sua azeda rivalidade com outro antropólogo português, o líder da MAT, António de Almeida. Como assinalam Castelo e Poloni nas suas contribuiçóes, as divergências entre os dois antropólogos cresciam desde que, em 1953, Cinatti 
acompanhara Almeida na primeira campanha da MAT e colidira com o estilo de ciência colonial seguida pelo seu concidadão. Esse (des)encontro com Almeida, em 1953, será crucial na viragem profissional de Cinatti para a antropologia. Nos anos seguintes, entre Cinatti e Almeida fervilharia um diferendo sobre a concepção de "antropologia" e uma competição pelo monopólio, no campo científico nacional, da autoridade antropológica sobre Timor Português. Por conseguinte, não é possível entender a história da antropologia em Timor colonial sem a figura quase omnipresente de Ruy Cinatti desde a década de 1960. Mas também não é possível compreendê-la sem a presença, igualmente dominante, de António de Almeida.

A figura de António de Almeida e o multifacetado universo disciplinar da MAT são abordados no ensaio de Rita Poloni. O artigo de Poloni constitui, ademais, um interessante complemento ao argumento utilizado por Castelo em relação a Cinatti, mas desta feita em relação ao seu rival (Almeida). Poloni coloca ênfase nas ansiedades políticas que motivaram Almeida a usar a exibição dos seus achados líticos em Timor na cena internacional para elevar, perante audiências nacionais, a sua autoridade antropológica sobre Timor Português. Poloni acompanha os trabalhos de terreno da primeira campanha da MAT em Timor concentrando-se em perceber o lugar que a arqueologia ocupou, sucessivamente, na pesquisa de campo e na publicaçáo científica dos trabalhos da missão. Inspirada (tal como Castelo) na teoria do campo científico de Pierre Bourdieu, Poloni argumenta que a pesquisa arqueológica realizada pela MAT sob orientaçáo de António de Almeida e Mendes Correia em 1953 - da qual os achados líticos pré-históricos na lagoa de Laga são o produto mais conhecido - compreende-se, acima de tudo, no quadro de uma estratégia políticocientífica, quase propagandística, para extrair "prestígio" da participação em fóruns científicos internacionais. A ciência da arqueologia era uma disciplina subalterna à antropologia física no programa da MAT e Almeida revelou-se um incompetente e mal preparado arqueólogo de campo. Contudo, apesar dessa relativa secundarização e do cepticismo que rodeou o acolhimento internacional dos seus trabalhos arqueológicos, as coleçôes líticas de Laga acabaram por ganhar um inesperado protagonismo estratégico. Por um lado, no modo como Almeida e Mendes Correia (eles próprios também destacadas figuras políticas do regime) engrandeceram, com desmesura, os resultados da MAT enquanto epítome da ciência nacional e da "ocupação científica" do ultramar português; por outro lado, servindo-se da apresentação das coleções em congressos internacionais para promover em Portugal as suas personas científicas, emprestando-lhes o véu imaginário do prestígio internacional. 
A manipulação estratégica dos achados arqueológicos é tanto mais evidente em face da impreparação metodológica, técnica e científica de Almeida para o estudo arqueológico de campo, à luz dos métodos internacionais da época (ainda que, como sublinha a autora, em termos estritamente nacionais, os métodos seguidos por Almeida em terreno ultramarino não diferissem do que acontecia na metrópole). Poloni mostra ainda como Almeida se apropriou da análise científica das peças produzida pelo arqueólogo francês Henri Breuil, de modo a dar continuidade a uma estratégia de autopromoção de autoridade antropológica sobre Timor. "As pesquisas arqueológicas em contexto timorense", Poloni conclui, "derivaram parte substantiva do seu significado dos discursos políticos sobre ela e acerca dela produzidos, mais do que da sua contribuição para o desenvolvimento das pesquisas científicas acerca da origem do homem indonésio”.

Após a primeira campanha de 1953-54, o projeto da MAT manteve-se ativo por quase mais duas décadas. Embora nunca com a mesma escala da primeira expedição, realizar-se-iam mais uma mão-cheia de "campanhas" sempre sob a liderança de António de Almeida. Prevaleceu a ênfase na "antropobiologia”; mas, fiel à visão ampla de Mendes Correia (falecido em 1960), a antropo(bio)logia das missões presumia necessária interligação entre os domínios do biológico e do cultural, pelo que as recolhas da MAT combinaram um interesse conexo na pré-história, na etnografia e na antropologia física. Dessas "campanhas" (a última das quais correspondente talvez à última visita de António de Almeida, em 1974) resultou a acumulação de um abundante e diversificado arquivo de informação de natureza antropológica - dados antropométricos, amostras de sangue, dados antroponímicos, recolhas de lendas, material lítico, mas também um vasto espólio de fotografias e filmes de natureza declaradamente "etnográfica". Este material viria a integrar as coleçóes do Centro de Estudos de Etnologia do Ultramar e, a partir de 1962, do seu sucessor institucional, o Centro de Antropobiologia, ambos dirigidos por Almeida e enquadrados pela Junta de Investigações do Ultramar.

É justamente acerca do significado da filmografia etnográfica - produzida não apenas pela MAT na década de 1950, mas significativamente também por Ruy Cinatti na década de 1960 - que nos convida a refletir Maria do Carmo Piçarra no seu artigo. Abordando o caso de Timor no quadro de uma exploraçáo ampla e comparada do arquivo fílmico colonial, a autora destaca dois aspectos que singularizam a filmografia portuguesa sobre Timor durante o Estado Novo. Em primeiro lugar, a relativa escassez e o carácter tardio de produção cinematográfica quando comparada com as colónias africanas; em segundo lugar, a relativa importância, na filmografia colonial de Timor, do género dos filmes científicos de natureza antropológica. 
Na década de 1930, Timor é timidamente exposta no écran através de imagens captadas nas exposiçóes coloniais que se organizaram na metrópole. Porém, é fugaz a presença de Timor na filmografia de propaganda colonial. Em Portugal, a crescente valorização simbólica de Timor e um mais generalizado interesse pelo território na Segunda Guerra Mundial oferecem um contexto propício para que Timor passe a interessar também ao olhar cinematográfico português. O exército produz imagens de guerra e surgem, após 1945, projetos de ficção. Em particular, o filme de ficção idealizado em 1947 (mas nunca concretizado) pelo realizador Fernando Garcia retrataria a vida na colónia nos tempos duros da ocupação japonesa - um projeto que, revela a autora, buscou a assessoria de "administradores coloniais especializados em assuntos etnográficos timorenses" para oferecer consistência à autenticidade das representaçôes cinematográficas dos nativos. $\mathrm{O}$ facto é indicador da autoridade etnográfica que era então reconhecida a administradores e militares coloniais. Para a autora, mas mais do que a ficção, será a filmografia de propaganda colonial e nacionalista a dominar a representação fílmica de Timor no pós-guerra.

É também nas décadas que sucedem a guerra que tem origem o "arquivo antropológico filmado" de Timor Português. É este composto por duas principais coleçôes: uma série de breves documentários realizados e produzidos no âmbito da MAT por António de Almeida, a partir de imagens captadas pelo técnico Salvador Fernandes, e a qual teve mais ampla difusão; e um extenso conjunto de imagens em filme realizado por Ruy Cinatti - filmado, cumpre assinalar, pelo mesmo técnico de câmara, Salvador Fernandes -, nunca editado nem publicado em vida pelo seu autor. Da comparação entre os dois arquivos fílmicos, a autora retira ilaçóes importantes. No caso dos filmes da MAT, estamos perante imagens onde política e ciência colonial se irmanam e onde a reprodução do registo da propaganda colonial do regime se confunde deliberadamente com registos etnográficos de costumes timorenses. Já no caso dos filmes captados por Cinatti, onde o som está ausente, ressaltam registos etnográficos de marca autoral, onde a cumplicidade e a empatia são aparentes. Esta diferença de registos acompanha o contraste entre os estilos de antropologia representados por Almeida e Cinatti, que, como acima vimos, os textos de Castelo e Poloni táo bem ajudam a evidenciar.

$\mathrm{O}$ artigo do investigador timorense Vicente Paulino, sobre as recolhas coloniais de lendas, mitos e tradiçóes orais timorenses no século XX, fecha o dossiê. Para Paulino, o trabalho etnográfico de missionários e administradores coloniais, ao transformar cultura oral em cultura escrita, resultou (não obstante as suas distorçôes e fragilidades) na formação de um valioso repositório documental de "literatura oral" timorense. O texto é escrito do ponto de vista de um académico 
timorense engajado com a valorização do património vernacular para a formação de uma cultura nacional leste-timorense. Por conseguinte, o artigo oferece uma ocasião oportuna para refletir sobre o problema não apenas da produção, mas também da circulaçáo leste-timorense das etnografias coloniais portuguesas na contemporaneidade, dentro e fora da academia. Segundo o autor, o repositório de saber vernacular disperso em artigos de cariz literário-etnográfico publicados na imprensa periódica de Timor e Portugal desde os anos 1940 (destacando-se, por exemplo, a revista católica Seara e o jornal $A$ Voz de Timor) constitui um aspecto precioso da memória coletiva leste-timorense e ainda uma fonte da história das populaçóes. Assim, inadvertidamente, os autores coloniais (mesmo amarrados a idealizaçôes nacionalistas e à retórica propagandística do regime imperial) criaram com as suas recolhas as bases culturais para a delimitação de "uma cultura timorense" independente; ou, por outras palavras, criaram as condiçóes para a subversão do seu próprio colonialismo etnográfico: "registando os géneros da literatura oral (lendas, contos, mitos, provérbios e anedotas) em textos", escreve Paulino, "os autores coloniais produziam fontes primárias de memória coletiva que propiciavam o trabalho político e intelectual de diferenciação cultural de 'um povo' no espaço e no tempo".

Não obstante a ampla diversidade de contos e narrativas recolhida por esses autores, Paulino chama a atenção para recorrências e semelhanças de conteúdos nas coletas etnográficas. Estas, para o autor, sugerem um sentido de unidade cultural leste-timorense. Um exemplo dessa transversalidade cultural é a conhecida lenda da origem de Timor que associa a ilha a um crocodilo transformado, e que as etnografias coloniais de missionários e administradores contribuíram para fixar e popularizar: "a referida lenda", argumenta Paulino, "é na verdade um amplo mito coletivo timorense, que se projeta do passado até à contemporaneidade. $\mathrm{O}$ que se nos afigura importante ainda é o modo como os meios de comunicação do período colonial português [...] funcionaram como agentes de consolidação deste imaginário lendário, como de outros relatos mitológicos da cultura timorense”. Porém, como reforça o autor, o presente e o futuro da relação entre literatura oral e literatura escrita timorense náo mais se encontram na palavra dos autores coloniais: está agora na voz de autores leste-timorenses no país.

\section{III}

Os ensaios de Timor etnográfico: antropologia e arquivo colonial expóem a condição política, mas também a natureza epistémica plural e plástica dos saberes etnográficos coloniais a dois níveis principais: (i) a inserção local, incluindo as 
formas de conhecimento, os agentes, as práticas de colonização e as interaçóes com as comunidades nativas; (ii) e a inserção metropolitana, intercolonial e transnacional dos saberes sobre Timor. A este título, os textos permitem situar a construção de um "Timor etnográfico" no século XX num campo científico e político que interligava vários lugares e várias escalas: um campo que ligava não só metrópole e colónia na forma imaginada de um "império", mas a própria metrópole e a própria colónia a outros espaços nacionais europeus e não europeus. Neste campo, distintos atores e instituições - em Timor, no império português e para além dele - disputavam autoridade sobre o terreno etnográfico em torno de diferentes versôes de "antropologia".

Decerto, conforme sublinhado, estes ensaios não correspondem a um inquérito cronológico ou mesmo temático cabal do arquivo, abundante e diverso, das etnografias coloniais sobre Timor-Leste. De fora ficam outros autores e obras, nomeadamente, e por exemplo, as etnografias coloniais do governador Afonso de Castro; do juiz e poeta Alberto Osório de Castro; do capitão e administrador colonial Armando Pinto Correia; do militar José Simóes Martinho; ou ainda dos missionários Jorge Barros Duarte e Artur Basilio de Sá - todos eles autores que assinaram algumas das mais importantes publicaçôes do género etnográfico colonial, desde a década de 1860 . De fora fica igualmente o projecto fugaz de um Centro de Estudos de Timor nos anos de 1950; os questionários etnográficos das décadas de 1910 e 1920; as dimensóes antropobiológicas da MAT; ou ainda a Missão Luso-Francesa da década de 1960 e as várias visitas dos etnógrafos internacionais.

Por examinar aqui, pois, ficam muitas outras histórias de antropologias coloniais de Timor. Ainda assim, parte deste fascinante universo etnográfico foi trabalhado pela equipa noutras publicaçóes do referido projeto e conexas aos estudos que compóem o presente dossiê (Cardoso, 2017; Castelo, 2011, 2017; Marques, Roque \& Roque, 2011; Paulino, 2011; Poloni, 2011; Roque, 2011a, 2011b, 2012a, 2012b, 2014, 2015; Roque \& Sousa, em preparação; Rosa, 2011, 2012, em preparação; Silva em preparação; Sousa, 2011; Viegas, 2011; Viegas $\&$ Feijó, em preparação). ${ }^{3}$ Com o conjunto ora apresentado ao leitor, trata-se, portanto, de abrir espaços interpretativos - mais do que fechar caminhos e delimitar fronteiras. Esperamos, pois, que este grupo de textos estimule novos investigadores a descobrir o fervilhante mundo das etnografias coloniais nos espaços de colonizaçáo portuguesa, não só em Timor, como noutros lugares.

Recebido em 15/03/2017

Aprovado em 12/10/2017 


\section{Notas}

1. Este artigo foi elaborado no âmbito do projeto As ciências da classificação antropológica em Timor Português (1894-1975), financiado pela Fundação para a Ciência e Tecnologia, Portugal (Ref. HC/0089/2009).

2. No recente volume Fieldwork in Timor-Leste, dedicado ao trabalho de terreno antropológico em Timor-Leste, coordenado por Nygaard-Christensen e Bexley (2017), por exemplo, está ausente uma reflexão sobre as etnografias coloniais do período português, embora as coordenadores reconheçam essa fragilidade. Uma abordagem às etnografias coloniais de Afonso de Castro, Alberto Osório de Castro, Armando Pinto Correia encontra-se no recente trabalho de Shepherd, no prelo.

3. Veja-se também o projeto online do Dicionário de biografias de antropologias de Timor em www.historyanthropologytimor.org.

\section{Referências}

ALMEIDA, Miguel Vale de. 2008. "Anthropology and ethnography of the Portuguesespeaking empire". In: P. Poddar, R. Patke e L. Jensen (ed.). A historical companion to postcolonial literature: continental Europe and its empires. Edinburgh: Edinburgh University Press. pp. 435-439.

CARDOSO, Hugo C. 2017. "Descriçôes portuguesas das línguas de Timor-Leste na transição dos séculos XIX e XX”. Moderna Sprak, 1:1-34.

CASTELO, Cláudia. 2011. "Ruy Cinatti: poeta, agrónomo e etnólogo, instigador de pesquisas em Timor". In: Vitor R. Marques; Ana Cristina Roque \& Ricardo Roque (ed.). Atas do Colóquio Timor: missóes científicas e antropologia colonial. Lisboa: IICT. Disponível em: http://www.historyanthropologytimor.org/wp-content/uploads/2012/01/16CASTELO_C.pdf. Acesso em: 12/07/2017.

. 2012. "Investigação científica e política colonial portuguesa: evoluçâo e articulaçôes, 1936-1974”. História, Ciências, Saúde - Manguinhos, 19(2):391-408.

. 2017. "Ruy Cinatti, the French-Portuguese Mission and the construct of East Timor as an ethnographic site". History and Anthropology, 1-23.

GUNN, Geoffrey. 2007. “The State of East Timor studies after 1999”. Journal of Contemporary Asia, 37(1):95-114.

. 2009. "Timor-Leste (former Portuguese East Timor): from colonial anthropology to an anthropology of colonialism". Review (Fernand Braudel Center), 32(3):289-337. 
HICKS, David. 2011. "A pesquisa etnográfica no Timor português". In: Kelly Silva \& Lúcio Sousa (ed.). Ita Maun Alin: o livro do irmão mais novo, afinidades antropológicas em torno de Timor-Leste. Lisboa: Colibri. pp. 31-46.

LEAL, João. 2000. Etnografias portuguesas (1870-1970): cultura popular e identidade nacional. Lisboa: Dom Quixote.

. 2006. "O império escondido: camponeses, construção da nação e o império na antropologia portuguesa”. In: Manuela Ribeiro Sanches (ed.). Portugal não é um país pequeno: contar o "império" na pós-colonialidade. Lisboa: Livros Cotovia. pp. 63-79.

MARQUES, Vitor R.; ROQUE, Ana Cristina \& ROQUE, Ricardo (ed.). 2011. Atas do Colóquio "Timor: Missöes Científicas e Antropologia Colonial". Lisboa: IICT. Disponível em: http://www.historyanthropologytimor.org. Acesso em: 12/07/2017.

MCWILLIAM, Andrew \& TRAUBE, Elizabeth (ed.). 2011. Land and life in TimorLeste: ethnographic essays. Canberra: ANU EPress.

NYGAARD-CHRISTENSEN, Maj \& BEXLEY, Angie. 2017. "Introduction: fieldwork in a new nation". In: . (ed.). Fieldwork in Timor-Leste: understanding social change through practice. Copenhagen: NIAS Press. pp. 1-31.

PAULINO. Vicente. 2011. "A imprensa católica Seara e a tradição timorense: 19491970". Anais Electrónicas do XI Conlab Salvador-Bahia: UFBA. Disponível em: http:// www.xiconlab.eventos.dype.com.br/resources/anais/3/1307067599_ARQUIVO_ AimprensacatolicaSearaeatradicaotimorense1949-1970.pdf Acesso em: 12/07/2017.

PEREIRA, Rui. 1989. "Colonialismo e antropologia: a especulação simbólica”. Revista Internacional de Estudos Africanos, 10-11:269-281.

. 1998. "Introdução à reedição de 1998". In: Jorge Dias. Os Macondes de Moçambique. Lisboa: CNCDP \& IICT. pp. V-LII.

. 2004-2005. "Raça, sangue e robustez: os paradigmas da antropologia física colonial portuguesa". Cadernos de Estudos Africanos, 7/8:210-241.

PINA-CABRAL, João de. 1991. Os contextos da antropologia. Lisboa: Difel.

POLONI, Rita. 2011. "A ciência vivida: a arqueologia e as missóes antropológicas do oficial à prática”. In: Vitor R. Marques; Ana Cristina Roque \& Ricardo Roque (ed.). Atas do Colóquio Timor: missóes cientificas e antropologia colonial. Lisboa: IICT. Disponível em: http://www.historyanthropologytimor.org/wp-content/uploads/2012/01/17POLONI_Rita.pdf. Acesso em: 12/07/2017.

ROQUE, Ricardo. 2001. Antropologia e império: Fonseca Cardoso e a expedição à Índia em 1895. Lisboa: Imprensa de Ciências Sociais. 
ROQUE, Ricardo. 2010. Headhunting and colonialism: anthropology and the circulation of human skulls in the Portuguese empire, 1870-1930. Basingstoke: Palgrave Macmillan.

2011a. "Etnografias coloniais, tecnologias miméticas: a administração colonial e os usos e costumes em Timor Leste no final do século XIX”. In: Kelly Silva \& Lucio Sousa (ed.). Ita Maun Alin: o livro do irmão mais novo, afinidades antropológicas em torno de Timor-Leste. Lisboa: Colibri. pp. 155-168.

.2011b. "José Celestino da Silva e o relatório sobre os usos e costumes de Timor".

In: Vitor R. Marques; Ana Cristina Roque \& Ricardo Roque (ed.). Atas do colóquio Timor: missöes cientificas e antropologia colonial. Lisboa: IICT/ICS. Disponível em: http:// www.historyanthropologytimor.org/wp-content/uploads/2012/01/10-ROQUE_R.pdf. Acesso em: 12/07/2017.

2012a. "Entangled with otherness: military ethnographies of headhunting in East Timor”. In: Ricardo Roque \& Kim A. Wagner (ed.). Engaging colonial knowledge: reading European archives in world history. Basingstoke: Palgrave Macmillan. pp. 254-278.

2012b. "Mountains and black races: anthropology's heterotopias in colonial East Timor". The Journal of Pacific History, 47(3):263-282.

2014. “Danças do Lorosa'e: imagem e folclore colonial, Timor 1950-1960". In: Nuno Faria (ed.). Imagens coloniais: revelaçóes da antropologia e da arte contemporânea, Guimarães. Cadernos CIAJG, A Oficina/Documenta, pp. 25-51.

2015. "Mimetic governmentality and the administration of colonial justice in East Timor, ca. 1860-1910". Comparative Studies in Society and History, 51(1):67-97.

ROQUE, Ricardo \& SOUSA, Lúcio. em preparação. “The stones of Afaloicai: colonial archaeology and the authority of ancient objects". In: Ricardo Roque \& Elizabeth Traube (eds.). Crossing histories and ethnographies: following colonial historicities in Timor-Leste.

ROQUE, Ricardo \& TRAUBE, Elizabeth (ed.). em preparação. Crossing histories and ethnographies: following colonial historicities in Timor-Leste.

ROSA, Frederico Delgado. 2011. "Missões de outra natureza: etnografias católicas em Timor 1917-1931”. Vitor R. Marques; Ana Cristina Roque \& Ricardo Roque (ed.). Atas do colóquio Timor: missóes científicas e antropologia colonial. Lisboa: IICT/ICS. Disponível em: http://www.historyanthropologytimor.org/wp-content/uploads/2012/01/09ROSA_FD.pdf. Acesso em: 12/07/2017.

. 2012. "Uruvatju e Tjiapu: genealogias invisíveis da etnografia missionária em Timor Leste”. In: A. Fidalgo Castro \& E. Legaspi Bouza (ed.). Léxico Fataluco-Português. Díli: Salesianos de Dom Bosco Timor-Leste. pp. 11-39. 
ROSA, Frederico Delgado. em preparação. "Catholic Luliks or Timorese relics? Missionary anthropology, destruction and self-destruction (c. 1910-1974)”. In: Ricardo Roque \& Elizabeth Traube (eds.). Crossing histories and ethnographies: following colonial historicities in Timor-Leste.

SCHOUTEN, Maria Johanna. 2001. "Antropologia e colonialismo em Timor português". Lusotopie, 157-171.

SHEPHERD, Christopher J. No prelo. Haunted houses and ghostly encounters: animism, colonialism and the ethnography of East Timor. Singapura: NUS Press.

SILVA, Kelly. em preparação. "Marriage exchanges, colonial fantasies and the production of East Timorese people in the 1970s Díli". In: Ricardo Roque \& Elizabeth Traube (eds.). Crossing histories and ethnographies: following colonial historicities in Timor-Leste.

SOUSA, Lúcio. 2011. "Objetos lulik, neolítico e casas sagradas: um episódio de antropologia colonial em António de Almeida”. In: Vitor R. Marques; Ana Cristina Roque \& Ricardo Roque (ed.). Atas do colóquio Timor: missóes cientificas e antropologia colonial. Lisboa: IICT/ICS. Disponível em: http://www.historyanthropologytimor.org/ wp-content/uploads/2012/01/18-SOUSA_L.pdf. Acesso em: 12/07/2017.

THOMAZ, Omar Ribeiro. 2001. “'O bom povo português': usos e costumes d'aquém e d'além-mar". Mana, 7(1):55-87.

VIEGAS, Susana de Matos. 2011. "Três etnografias nas décadas de 1960-1970: os Fataluku”. In: Vítor Rosado Marques, Ana Cristina Roque \& Ricardo Roque (eds.). 2011. Actas do Colóquio Timor: missóes científicas e antropologia colonial. Lisboa: IICT/ ICS-UL, edição digital [DVD].

VIEGAS, Susana de Matos \& FEIJÓ, Rui. em preparação. "Funerary posts and Christian crosses: Fataluku cohabitations with Catholic missionaries after World War II”. In: Ricardo Roque \& Elizabeth Traube (eds.). Crossing histories and ethnographies: following colonial historicities in Timor-Leste.

VIEGAS, Susana de Matos \& PINA-CABRAL, João de. 2014. "Na encruzilhada portuguesa: a antropologia contemporânea e a sua história”. Etnográfica, 18(2):311-332. 


\section{Resumo}

Este artigo examina o universo das etnografias coloniais em Timor-Leste, chamado Timor Português, durante o período da administração colonial portuguesa no século XX. Argumentase a importância de uma história da antropologia atenta à pluralidade de práticas e saberes etnográficos em situaçáo colonial. $\mathrm{O}$ artigo discute pesquisa recente sobre etnografias coloniais no império português tendo como referência os contributos contidos no dossiê de artigos Timor Etnográfico: Antropologia e Arquivo Colonial.

\section{Abstract}

This article examines the world of colonial ethnographies in Timor-Leste, designated Portuguese Timor, during the Portuguese colonial period in the twentiethcentury. It argues for the significance of a history of anthropology that focuses on the plurality of ethnographic practices and knowledge forms in colonial situation. The article discusses current research on colonial ethnographies in the Portuguese Empire, with reference to the articles and contributions contained in the special issue Ethnographic Timor: Anthropology and the Colonial Archive.

Keywords: colonial ethnography, history of anthropology, Portuguese

Empire, Timor-Leste.
Palavras-chave: etnografia colonial, história da antropologia, Império Português, Timor-Leste 